\title{
O PAPEL DO TRADUTOR-INTÉRPRETE DE LIBRAS EM SALA DE AULA INCLUSIVA
}

\author{
THE ROLE OF THE BRAZILIAN SIGN LANGUAGE \\ INTERPRETER/TRANSLATOR IN AN INCLUSIVE CLASSROOM
}

\section{Resumo}

Letícia Jovelina Storto*

Deisiane Neves Menezes ${ }^{* *}$

Leila Cristina Matias ${ }^{* * *}$

Margarete Cristina Morais ${ }^{* * * *}$

Solange Aparecida de Souza Monteiro ${ }^{* * * * *}$

Este trabalho tem como objetivo principal pesquisar sobre o papel do tradutor-intérprete de Libras em sala de aula inclusiva. Para tanto, foram realizadas pesquisas bibliográfica e de campo, utilizando-se um questionário como instrumento de coleta de dados. O questionário foi elaborado para que se obtivessem informações sobre aspectos da formação e da atuação desses profissionais, que têm se tornado cada vez mais necessários em tempos de inclusão. A pesquisa revelou que, do ponto de vista dos entrevistados, o ensino regular tem sido benéfico aos surdos, proporcionando-lhes melhores condições de aprendizagem e desenvolvimento, embora alguns professores e agentes de educação ainda não estejam preparados para receber esses alunos de forma adequada, em turmas regulares da educação básica.

Palavras-chave: Ensino. Inclusão. Libras. Tradutor-intérprete de Libras.

\section{Considerações Iniciais}

Em conformidade com as conquistas da sociedade moderna, o ensino tem procurado se adaptar às transformações, almejando melhoras na qualidade do ensino. Uma dessas conquistas é a inclusão daqueles que outrora foram ignorados ou segregados. Com a inclusão,

\footnotetext{
* Doutora em Estudos da Linguagem (UEL). Professora adjunta da Universidade Estadual do Norte do Paraná (UENP). E-mail: leticiajstorto@gmail.com

** Licenciada em Química Industrial pela UNOPAR, campus Londrina. Professora da Educação Básica. E-mail: neves-menezes@hotmail.com

*** Licenciada em Estética e Imagem pessoal pela UNOPAR, campus Londrina. E-mail: leiloka.bony@hotmail.com

**** Graduada em Gestão Ambiental pela Universidade Metodista de São Paulo. E-mail: margaretedasilva.morais@gmail.com

${ }^{* * * * *}$ Licenciada em Pedagoga - professora no Instituto Federal de Educação Ciência e Tecnologia de São Paulo - (IFSP), campus Araraquara. E-mail: solmonteiro@ifsp.edu.br
} 
pretende-se uma escola que promova a formação do indivíduo, para que ele se torne um cidadão ético, ativo socialmente e politicamente instruído. No entanto, quando se trata do atendimento a alunos com deficiência, transtornos globais do desenvolvimento e altas habilidades ou superdotação (BRASIL, 2013), o Brasil ainda está longe de realizar o que seria desejável. Muitas vezes esses estudantes procuram escolas especiais para sua formação básica, as quais estão mais bem preparadas para atender as suas necessidades.

No Brasil, foram criadas leis que asseguram o ingresso de estudantes com deficiência, transtornos globais do desenvolvimento e altas habilidades ou superdotação no ensino regular, garantindo, assim, sua educação e inclusão. No tocante ao aluno surdo, para que o ensino ocorra de forma eficaz faz-se necessária o emprego da língua brasileira de sinais (Libras) e a presença de um tradutor-intérprete de Libras (TIL). A figura desse profissional é recente no país e sua função é traduzir e interpretar a fala docente para o estudante surdo por meio da Libras, mediando linguisticamente o processo de ensino/aprendizagem e a interação verbal entre os envolvidos (aluno surdo/aluno ouvinte-professor/comunidade escolar).

A Libras, no Brasil, ganhou destaque apenas no século XXI, a partir de 2005, ano em que se estabeleceu, por meio do Decreto $n^{\circ}$ 5.626, de 22 de dezembro de 2005 (BRASIL, 2005), o ensino de Libras nas matrizes curriculares dos cursos de licenciatura em diferentes áreas do conhecimento. Ainda mais recente é a discussão sobre a inclusão do ensino dessa língua na educação básica (BRASIL, 2018) ${ }^{1}$. O objetivo dessas leis era ampliar o número de usuários de Libras na nação brasileira, a fim de melhor incluir a pessoa surda.

Questionamentos a respeito da formação de profissionais tradutores-intérpretes de Libras são relativamente recentes. Qual a formação dos profissionais dessa área que atuam em turmas regulares do ensino básico? Esses profissionais têm formação em áreas pedagógicas? Como é a sua interação com os estudantes (surdos e ouvintes) e com os professores? Para os envolvidos no processo de ensino/aprendizagem de um aluno surdo, está clara a função dos tradutores-intérpretes de Libras? Essas são questões que impulsionaram esta pesquisa, realizada em Londrina, no estado do Paraná. Buscar respostas para essas questões é o objetivo deste trabalho.

\section{A Língua Brasileira de Sinais e o Tradutor-intérprete de Libras}

De acordo com Quadros (2004, p.8), compreende-se por línguas de sinais as que são utilizadas pelas comunidades surdas e que "apresentam as propriedades específicas das 
línguas naturais, sendo, portanto, reconhecidas enquanto línguas pela Linguística”. Entre as propriedades de uma língua, podem-se citar: representar uma comunidade de usuários; ter uma gramática própria; ser decomponível em unidades menores, favorecendo sua análise; ser suscetível à classificação; ter uma fonologia ${ }^{2}$; ser pluridimensional (ter enunciador, enunciatário, contexto sociodiscursivo); ser multifacetada, heterogênea e variável; produzir conteúdo e mensagens (textos, discursos) variáveis e ilimitados (adaptado de PETTER, 2004).

Num discurso semelhante ao de Petter (2004), sobre as propriedades das línguas naturais, Quadros (2004, p.8) afirma que essas línguas “são recursivas (a partir de um número reduzido de regras, produz-se um número infinito de frases possíveis), são criativas (ou seja, independentes de estímulo), dispõem de uma multiplicidade de funções (função argumentativa, função poética, função conotativa, função informativa, função persuasiva, função emotiva, etc.) e apresentam dupla articulação (as unidades são decomponíveis e apresentam forma e significado)".

Quadros (2004, p.7) distingue o profissional "intérprete" do "intérprete de Libras". No que tange ao primeiro, trata-se da "pessoa que interpreta de uma língua (língua fonte) para outra (língua alvo) o que foi dito" 3 , enquanto o intérprete de Libras é aquele "que interpreta de uma dada língua de sinais para outra língua, ou desta outra língua para uma determinada língua de sinais" ". As diferenças entre o "tradutor", o "tradutor-intérprete" e o "tradutorintérprete de língua de sinais", são apresentadas por Quadros (2004, p.11) por meio de um esquema:

Tradutor - Pessoa que traduz de uma língua para outra. Tecnicamente, tradução refere-se ao processo envolvendo pelo menos uma língua escrita. Assim, tradutor é aquele que traduz um texto escrito de uma língua para a outra.

Tradutor-intérprete - Pessoa que traduz e interpreta o que foi dito e/ ou escrito.

Tradutor-intérprete de língua de sinais - Pessoa que traduz e interpreta a língua de sinais para a língua falada e vice-versa em quaisquer modalidades que se apresentar (oral ou escrita).

O tradutor-intérprete de Libras é o profissional fluente na língua de sinais, dotado de competências e habilidades tradutoras, comunicativas e interacionais. Ele também apresenta habilidades de tradução em tempo real (interpretação simultânea) ou em um espaço de tempo (interpretação consecutiva), tanto da língua de sinais para a língua oral quanto da oral para sinais. 
De acordo com Filietaz (2008), a profissão de tradutor-intérprete surgiu devido à necessidade de a comunidade surda ter um profissional como auxiliar no seu processo de comunicação. Acrescente-se a isso a necessidade de mediar a interação escolar e social. "Para que isso se tornasse realidade, fez-se necessário que houvesse a oficialização da Língua Brasileira de Sinais - Libras" (FILIETAZ, 2008, p.3). Nos últimos anos, a presença de um profissional capacitado para interpretar e traduzir a Libras tornou-se imprescindível na esfera política, na religiosa, na educacional etc. Isso se deve à necessidade de propiciar à comunidade surda maior acesso ao ensino e as mais variadas interações sociais e sociocomunicativas, principalmente de forma inclusiva, tanto em âmbito escolar quanto em âmbito social e profissional. Some-se a esse fator a realidade de a sociedade dispor de poucos TIL com preparo e formação pedagógica necessária para assumir a função.

Face a tais necessidades e tendo em vista a relevância do trabalho do TIL, a legislação brasileira passou a exigir atributos e requisitos específicos para a formação desse profissional, para que ele seja preparado de forma adequada e competente desempenhar bem seu papel, o qual deve estar definido e delimitado, a fim de que ele consiga mediar a comunicação entre o aluno surdo e o ensino (processos de ensino/aprendizagem, seus pares na escola, professores, comunidade escolar etc.). O Decreto n 5.626, de 22 de dezembro de 2005 (BRASIL, 2005, s/p), prevê em seu Artigo 18 que:

[...] a formação de tradutor e intérprete de Libras - Língua Portuguesa, em nível médio, deve ser realizada por meio de: I - cursos de educação profissional; II - cursos de extensão universitária; e III cursos de formação continuada promovidos por instituições de ensino superior e instituições credenciadas por secretarias de educação. Parágrafo único. A formação de tradutor e intérprete de Libras pode ser realizada por organizações da sociedade civil representativas da comunidade surda, desde que o certificado seja convalidado por uma das instituições referidas no inciso III.

O trabalho do TIL não se restringe ao conhecimento da Libras e de sua estrutura gramatical, não se trata apenas de a decodificar, mas se estende a conhecer também "valores culturais, costumes e idiossincrasias da comunidade surda, buscando não apenas garantir a 'decodificação' dos aspectos estruturais das línguas em questão, mas, sobretudo seu aspecto discursivo, a constituição de sentidos instituída na relação entre os falantes" (FILIETAZ, 2008, p.2). Além disso, para a autora, o intérprete tem uma função mediadora em sala de aula, 
devendo interpretar a aula, e não a ministrar ao estudante surdo. "Seu papel é o de mediador da aprendizagem e não de agente", de professor (FILIETAZ, 2008, p.2).

Conforme supracitado, os primeiros intérpretes de língua de sinais surgiram da necessidade de comunicação do indivíduo surdo. De acordo com Filietaz (2008, p.3), por não ser uma profissão ainda oficializada, no início, não havia cursos de formação específica para intérpretes de língua de sinais; por conseguinte, o número de pessoas habilitadas para exercer a função era muito limitado 5 . O trabalho desses profissionais se dava de forma voluntária e em situações informais, sendo realizado por filhos de pais surdos, amigos, membros da família ou figuras religiosas. Essa informalidade explica a dificuldade de os intérpretes em "manter atitudes de confidencialidade, imparcialidade ou de garantir o direito da pessoa surda em saber e compreender todo o processo" (FRISHBERG, 1990, p.10 apud ALMEIDA, 2010, p.16).

Para Frishberg (1990 apud ALMEIDA, 2010, p.16), o desenvolvimento na área de interpretação das línguas de sinais se justificou por se reconhecer que as pessoas surdas eram impedidas de exercer seus direitos plenos de cidadãos por conta da barreira de comunicação existente entre elas e as pessoas ouvintes. Filietaz (2008, p.4) observa que, ao final da década de 1990.

[...] muitos Surdos passaram a solicitar Intérprete em várias situações, não mais induzidos pelos ouvintes, mas movidos por seus próprios interesses, diferentemente do que ocorria até então. O Intérprete, por sua vez, passa a ter seu papel de mediador na comunicação com as pessoas ouvintes fortalecido, passando a ser visto como um elemento fundamental nesta interação.

De acordo com Almeida (2010), a primeira escola para surdos no Brasil foi o Imperial Instituto de Surdos-Mudos (atual Instituto Nacional de Educação de Surdos - INES), criada pela Lei $\mathrm{n}^{\circ}$ 839, de 26 de setembro de 1857, por Dom Pedro II, no Rio de Janeiro, proposta por um professor surdo e ex-aluno do Instituto Nacional de Surdos-Mudos de Paris, Eduard Huet. Na história do INES, o primeiro registro indicando a presença de intérpretes ocorreu na década de 1950, prática realizada por professores de educação física, por iniciativa própria:

Há de se destacar o trabalho realizado pelos profissionais de Educação Física no Instituto. Muitos deles se tornaram referências importantes para os alunos. A proximidade comunicativa era tamanha que eles atuavam como intérpretes dos alunos nas cerimônias realizadas na Instituição e em eventos particulares dos alunos. No tempo em que a comunicação gestual era desestimulada nas salas de aulas, esses profissionais de maneira espontânea, chamavam para si a responsabilidade de 
garantir aos alunos os sentidos do que estava sendo dito em língua oral pelos ouvintes (ROCHA, 2009, p.78).

Segundo Rosa (2005, p.18), em nosso país, as práticas de interpretação mais antigas se vinculam também às instituições religiosas e tiveram início no começo da década de 1980 . Até recentemente, a formação do intérprete se dava, basicamente, em espaços religiosos. Almeida (2010) afirma que os pastores intercediam em nome do surdo e, muitas vezes, chegavam a tomar decisões em seu nome, reforçando a crença de que os indivíduos surdos não eram capazes de cuidar de seus próprios negócios ou de assuntos pessoais sem a intervenção de um ouvinte.

A fluência e o domínio em língua de sinais desses profissionais foram adquiridos por meio do contato direto com os surdos, enquanto as formas de interpretar, na prática, foram construídas com o auxílio da própria comunidade. $\mathrm{Na}$ época, não se acreditava ser necessária uma formação adequada de profissionais intérpretes de língua de sinais; logo, não havia uma preocupação com sua formação, bastava frequentar as associações de surdos ou conviver com pessoas surdas.

O contato com a comunidade surda e a língua de sinais levou os profissionais a desenvolverem trabalhos voluntários na Federação Nacional para a Educação e Integração do Surdo (Feneis), que organizou, em 1988, o I Encontro Nacional de Intérpretes de Língua de Sinais, o qual "propiciou, pela primeira vez, o intercâmbio entre alguns intérpretes do Brasil e a avaliação sobre a ética do profissional intérprete" (QUADROS, 2004, p.14).

O conceito sobre a formação do profissional do tradutor-intérprete de Libras começou a se alterar mais recentemente, conforme se lê na página eletrônica da Feneis ${ }^{6}$, que aponta como requisito necessário à formação desse profissional o conhecimento mais aprofundado da Libras. A Legislação nacional, recentemente, também apresenta determinações para a formação desse profissional. No Decreto 5.626, de 22 de dezembro de 2005 (BRASIL, 2005), em seu Art. 17, lê-se: “a formação do tradutor e intérprete de Libras - Língua Portuguesa deve efetivar-se por meio de curso superior de Tradução e Interpretação, com habilitação em Libras - Língua Portuguesa”.

Lacerda (2010), fundamentada na Legislação brasileira, apresenta aspectos importantes para a formação do tradutor-intérprete de língua de sinais (Libras/Português) (TILS) e discute a questão das relações interpessoais entre o profissional e a comunidade surda. Acerca disso, Lacerda (2010, p.139) acrescenta que "a FENEIS indica que os 
interessados devem frequentar cursos de língua de sinais e conviver com pessoas surdas nas associações, para desenvolverem um uso efetivo da língua em situações de comunicação concretas”. Quadros (2004, p.43-44) apresenta algumas posturas éticas no desempenho da função de TILS: a) ser imparcial; b) ser discreto em sua forma de atuar; c) ter postura quanto ao local da atuação; d) ser fiel à produção tanto em Libras quanto em língua portuguesa, mantendo a coerência textual e semântica; e) organizar o espaço.

Nos termos da lei, foi a partir da Lei da Acessibilidade, ou seja, a Lei nº 10.098, de 19 de dezembro de 2000 (BRASIL, 2000) que algumas universidades e faculdades passaram a aceitar profissionais tradutores-intérpretes de Libras em suas salas de aula, como forma de garantir ao surdo o direito à educação superior, como já determinava a lei. Entretanto, somente a partir da promulgação do Decreto 5.626, de 22 de dezembro de 2005 (BRASIL, 2005), a presença desse profissional nos espaços educacionais nos diferentes níveis de ensino só foi garantida pela legislação. Segundo o primeiro parágrafo do Artigo 14 do Decreto 5.626 (BRASIL, 2005):

\begin{abstract}
Para garantir o atendimento educacional especializado e o acesso previsto no caput, as instituições federais de ensino devem: [...] III - prover as escolas com: a) professor de Libras ou instrutor de Libras; b) tradutor e intérprete de Libras - Língua Portuguesa; c) professor para o ensino de Língua Portuguesa como segunda língua para pessoas surdas; e d) professor regente de classe com conhecimento acerca da singularidade linguística manifestada pelos alunos surdos; IV - garantir o atendimento às necessidades educacionais especiais de alunos surdos, desde a educação infantil, nas salas de aula e, também, em salas de recursos, em turno contrário ao da escolarização; V - apoiar, na comunidade escolar, o uso e a difusão de Libras entre professores, alunos, funcionários, direção da escola e familiares, inclusive por meio da oferta de cursos; VI - adotar mecanismos de avaliação coerentes com aprendizado de segunda língua, na correção das provas escritas, valorizando o aspecto semântico e reconhecendo a singularidade linguística manifestada no aspecto formal da Língua Portuguesa; VII - desenvolver e adotar mecanismos alternativos para a avaliação de conhecimentos expressos em Libras, desde que devidamente registrados em vídeo ou em outros meios eletrônicos e tecnológicos; VIII - disponibilizar equipamentos, acesso às novas tecnologias de informação e comunicação, bem como recursos didáticos para apoiar a educação de alunos surdos ou com deficiência auditiva.
\end{abstract}

Atualmente, a profissão do tradutor-intérprete de Libras está ligada à Coordenadoria Nacional para Integração da Pessoa Portadora de Deficiência (CORDE), órgão governamental, sobre o qual foi instituída uma Lei que determina tratamento prioritário e adequado ao aluno com deficiência, transtornos globais do desenvolvimento e altas habilidades ou superdotação no ensino regular, bem como prevê "a inclusão, no sistema 
educacional, da educação especial como modalidade de educação escolar que permeia transversalmente todos os níveis e as modalidades de ensinos” (BRASIL, 2006, p.200).

\section{Materiais e Métodos}

Como instrumento de coleta de dados, foi empregado um questionário estruturado com dez questões discursivas. Tal ferramenta buscou levantar informações a respeito da realidade do tradutor-intérprete de Libras (TIL) que atua em escolas de ensino público e regular da cidade de Londrina, Norte do Paraná. As perguntas buscaram identificar o perfil dos entrevistados para descrever suas características, como fatores motivacionais que os levaram a escolher a profissão de TIL, as contribuições da profissão etc. Para tanto, mediante um recurso digital do Google Docs, foi desenvolvido um questionário eletrônico, o qual foi enviado (em meados de 2016) aos profissionais citados.

Considerando isso, esta pesquisa configura-se como uma pesquisa de campo cujos dados foram descritos mediante uma abordagem qualitativa (GIL, 2008; MARCONI; LAKATOS, 2003). No que tange aos seus objetivos, esta pesquisa é classificada como descritiva, a qual tem "como objetivo primordial a descrição das características de determinada população ou fenômeno ou o estabelecimento de relações entre variáveis" (GIL, 2008, p.28). A pesquisa bibliográfica foi empregada como técnica auxiliar, uma vez que "toda pesquisa implica o levantamento de dados de variadas fontes" (MARCONI; LAKATOS, 2003, p.174).

Uma das limitações da pesquisa foi o pouco contato que os pesquisadores tiveram com os TILs, devido às dificuldades de acesso a esses profissionais e também pelo fato de somente três deles terem respondido ao questionário enviado eletronicamente. Assim, no próximo tópico, são apresentadas e discutidas as respostas dos três profissionais tradutores-intérpretes de Libras que participaram deste estudo.

\section{Discussão dos Dados}

Os dados obtidos por meio do questionário foram analisados e cruzados de forma a se obter um consenso entre as respostas e as informações pertinentes à formação e atuação do profissional tradutor-intérprete de Libras no contexto já informado. As respostas foram recebidas e alinhadas de modo a respeitar o anonimato dos participantes. 
Inicialmente, os entrevistados foram questionados sobre a escolha da profissão. Conforme se observa no Quadro 1, os profissionais responderam que os motivos foram: a beleza da língua, a necessidade de haver profissionais de Libras nas escolas de ensino regular, o contato próximo com algum indivíduo surdo na igreja ou na escola.

Quadro 1: razões para a escolha da profissão de tradutor-intérprete de Libras

\section{O que te levou a ser tradutor-intérprete de Libras?}

TIL1: Em um primeiro momento é uma língua linda. Em um segundo momento a necessidade de intérpretes para atuar nas escolas de ensino regular. Os surdos ficavam e ficam excluídos.

TIL2: O contato com o surdo no ensino regular e na igreja.

TIL3: A minha igreja precisava de intérpretes de Libras para auxiliar durante cultos e na escola dominical e meu serviço ofereceu o curso.

Fonte: elaborado pelos autores com base nos dados da pesquisa.

Os dados mostram que o interesse parte, a princípio, de questões exteriores aos entrevistados, não tendo relação com aspectos familiares ou acadêmicos. Chama a atenção a presença da igreja e do religioso nas respostas, mostrando que tal esfera da atividade humana tem impulsionado e apoiado a formação de profissionais na área de Libras, seja como tradutor, seja como intérprete ou tradutor-intérprete.

A segunda questão objetivou levantar informações sobre o tempo de experiência dos TIL na área e local de formação. As respostas apresentadas no Quadro 2 mostram que os entrevistados não são iniciantes no conhecimento da Libras, já que o tempo mínimo citado foi de dez anos e o máximo, vinte anos. Essa informação é importante porque dá maior confiabilidade aos dados apresentados nas respostas seguintes. Relativo ao local de informação, os entrevistados trouxeram respostas distintas: formação no Instituto Londrinense de educação de Surdos, formação oferecida pela igreja de TIL2 e pela empresa em que TIL3 trabalha. Isso demonstra que a Universidade ainda não foi, para os participantes desta pesquisa, um local de formação. Isso se deve, muito provavelmente, por ser recente a promulgação do Decreto $n^{\circ}$ 5.626, de 22 de dezembro de 2005 (BRASIL, 2005) e por ser necessário algum tempo para as universidades formarem seus primeiros profissionais capacitados na área. 
Quadro 2: formação dos tradutores-intérpretes de Libras participantes do estudo

\section{Há quanto tempo você se formou? Como e onde se deu sua formação?}

TIL1: Há 13 anos, na igreja e depois no ILES (Escola de Surdos).

TIL2: Há 20 anos atuo como professora bilíngue na disciplina de História. E atuei 2 anos como intérprete no curso Técnico de administração e magistério.

TIL3: 10 anos, na empresa onde trabalhava.

Fonte: elaborado pelos autores com base nos dados da pesquisa.

A terceira questão proposta dizia respeito às dificuldades que os TIL encontraram em sua formação para atuar na área. De forma geral, as respostas, transcritas no Quadro 3, mostram que a maior dificuldade de formação dos entrevistados foi a aprendizagem da Libras, isso relacionado aos aspectos teóricos da língua, às habilidades exigidas para seu aprendizado (tais como a boa movimentação das mãos, boa expressão facial etc.), dificuldades em compreender a coerência da língua de sinais e na distinção entre os sinais. Mais especificamente, a respeito disso, pode-se dizer que, no aprendizado de uma segunda língua, é algo muito comum a confusão entre os elementos da língua (mistura lexical, confusão morfossintática, estilística, semântica etc.). Também é habitual a influência da língua natural do aprendiz, no caso a língua portuguesa, no aprendizado de outra língua.

Quadro 3: dificuldades e problemas encontrados na formação do tradutor-intérprete de Libras

\section{Quais as dificuldades e pontos negativos encontrados durante sua formação?}

TIL1: O conhecimento teórico sobre a língua de sinais. Dificuldade na aquisição da língua e falta de contato com surdos.

TIL2: A tradução. A maior falha na minha formação foi que aprendi muitos sinais e poucos classificadores. Às vezes eu complico a mensagem. Muitos sinais.

TIL3: Na habilidade das mãos, pois não tinha muita agilidade.

Fonte: elaborado pelos autores com base nos dados da pesquisa. 
Sobre o preparo dos profissionais do ensino regular para receber alunos surdos em turmas da educação básica, os participantes deste estudo foram unânimes em responder que os profissionais da comunidade escolar não estão preparados e não sabem como interagir com o discente surdo. Os entrevistados indicaram, ainda, a ausência de interesse por parte de escolas e profissionais em incluir o aluno surdo, criando-se uma ambiente de maior exclusão escolar e social que de inclusão. Isso acontece porque a educação inclusiva, da forma como está organizada, "mascara as reais necessidades dos alunos surdos", segundo as palavras do TIL 1, transcritas do Quadro 4.

Quadro 4: recebimento do estudante surdo em turmas regulares na opinião do tradutor-intérprete de Libras

\section{Para você, os profissionais envolvidos na educação estão preparados para receber o estudante surdo?}

TIL1: Não, a educação inclusiva mascara as reais necessidades dos alunos surdos.

TIL2: Não, pois há pouco interesse na inclusão social.

TIL3: A estrutura do ensino regular não contribui.

Fonte: elaborado pelos autores com base nos dados da pesquisa.

A questão seguinte do questionário abordou a relação entre o professor e o tradutorintérprete de Libras e entre o tradutor-intérprete de Libras e o aluno surdo. Os participantes afirmaram que, de modo geral, essas relações são positivas e recíprocas. Em sua resposta, TIL3 afirma que, para o sucesso dessas relações, a língua portuguesa em sua modalidade oral é importante na interação com o discente surdo. Na verdade, a figura do TIL é imprescindível, pois sem ela não haveria relação e o processo de ensino do estudante surdo estaria restrito a centros especializados.

Também cumpre comentar que, nessa esfera, é mais eficaz o papel do tradutorintérprete de Libras do que apenas do tradutor ou apenas do intérprete. Isso porque não basta decodificar a língua de sinais, não basta traduzi-la para o português e o inverso também não se mostra suficiente. É preciso alguém que seja de fato fluente em Libras, com competências e 
habilidades tradutórias, comunicativas e interacionais, com conhecimento da cultura e da comunidade surda.

Quadro 5: interação do tradutor-intérprete de Libras com o professor regente e com o estudante surdo

Como é a relação entre o professor e o tradutor-intérprete de Libras (TIL)? E esse profissional (TIL) e o aluno surdo?

TIL1: A relação é normalmente boa.

TIL2: É uma relação boa, o respeito é recíproco.

TIL3: Geralmente nos damos bem, também por haver comunicação oral.

Fonte: elaborado pelos autores com base nos dados da pesquisa.

Quando questionados sobre a relação do aluno ouvinte com o aluno surdo, as respostas, transcritas no Quadro 6, foram diferentes: TIL1 considerou "boa", mas podendo ser melhorada; TIL2 afirmou que a responsabilidade recai toda sobre o surdo, que deve envolver seus colegas ouvintes a fim de que se interessem pela Libras (e até mesmo pelo próprio surdo); TIL3 avalia a relação como ruim. Vale comentar que TIL3, apesar de contar com dez anos de experiência na área no momento da pesquisa, era quem tinha o menor tempo trabalhando como TIL. A maior experiência era a de TIL2, que avalia de modo positivo essas relações. Em sua resposta, TIL 1 mostra que há tentativas por parte do aluno ouvinte de interagir com o surdo, ainda que não seja por meio da Libras. Para TIL3, essa interação é "distante".

Mais um dado importante é o fato de os entrevistados chamarem a Libras de linguagem, mostrando não compreender o status linguístico da Libras, língua brasileira de sinais. Isso se deve ao fato de sua formação, não acadêmica, ter sido simultânea ou anterior à Lei da Libras.

Quadro 6: interação entre aluno surdo e ouvinte em escola regular

Como é a interação entre o aluno ouvinte e o aluno surdo? É benéfica a ambos?

TIL1: É limitada devido à falta de conhecimento da linguagem de sinais do aluno ouvinte, mas pode se 
tornar benéfica a partir do momento que esse aluno tiver acesso a essa linguagem.

TIL2: É interessante pois o aluno ouvinte se esforça para comunicar-se com o surdo e acabam criando "maneiras" para que isso ocorra, acabam se interessando pela linguagem.

TIL3: É distante, pois precisa ser intermediada pelo intérprete.

Fonte: elaborado pelos autores com base nos dados da pesquisa.

Quanto ao papel do TIL em sala de aula, os profissionais descreveram, de modo geral, a mesma postura: a de que a função do TIL é somente intermediar a comunicação do aluno surdo com o professor e a comunidade escolar, de modo a atuar como um profissional neutro. No Quadro 7, o TIL 3 afirma que "o intérprete é vazio", algo citado por alguns pesquisadores da área, pois ensinar não é um dos papéis do tradutor-intérprete de Libras. Quadros (2004, p.29) afirma que, em uma sala de aula inclusiva, "os professores são professores e os intérpretes são intérpretes".

Em sua resposta, o entrevistado TIL 2 observa que, na prática, o TIL tem assumido o papel de professor, auxiliando a aprendizagem do aluno surdo, uma vez que "o professor do ensino regular desconhece a singularidade do indivíduo com surdez". Além disso, não conhece a Libras e não entende a função do TIL, cedendo a ele o seu lugar de docente.

Na sétima pergunta, ao comparar as respostas dos entrevistados, pode-se inferir que a maior experiência na área dá condições ao TIL2 de tecer uma resposta que aponta para as funções do intérprete, apresentadas pela Legislação brasileira e por autores que pesquisam o assunto, tais como Almeida (2010), Lacerda (2010) e Rocha (2009).

Quadro 7: Papel do tradutor-intérprete de Libras numa sala de aula regular

Qual o papel do tradutor-intérprete de Libras numa sala de aula regular? Como ele atua e auxilia nos processos de ensino/aprendizagem do estudante surdo?

TIL1: Intermediar a comunicação entre o surdo e a comunidade escolar.

TIL 2: No ensino regular o intérprete realiza a comunicação entre o surdo e a comunidade escolar. Segue o código de ética intermediando a comunicação entre surdo e ouvinte. No contexto de sala de aula o intérprete deve assumir uma postura de neutralidade sendo fiel ao conteúdo da comunicação. Entretanto na prática o intérprete assume o papel de professor auxiliando o surdo no processo de ensino/aprendizagem uma vez que o professor do ensino regular desconhece a singularidade do indivíduo com surdez. 
TIL3: Intermediar a comunicação entre o surdo e a comunidade escolar, "o intérprete é vazio".

Fonte: Elaborado pelos autores com base nos dados da pesquisa.

Questionados sobre sua participação no planejamento pedagógico do ensino de estudantes surdos, os TIL responderam que não têm essa participação, pois sua função não é essa. Quadros (2004, p.61) afirma que “o intérprete assumirá somente a função de intérprete que em si já se basta e caso seja requerido um professor que domine língua de sinais que este seja contratado como tal". Segundo os entrevistados, na maior parte das vezes, a função do TIL é essa: estabelecer a comunicação do aluno surdo com a comunidade escolar por meio da tradução-interpretação da Libras para a língua portuguesa e da língua portuguesa para a Libras.

Quadro 8: Participação do tradutor-intérprete de Libras no planejamento pedagógico escolar

\section{O tradutor-intérprete de Libras participa do planejamento pedagógico escolar?}

TIL1: Não, sua responsabilidade é fazer a comunicação entre surdos e ouvintes com fidelidade.

TIL2: Não. O intérprete deve ser neutro. Sujeito vazio. Sua responsabilidade é com a comunicação entre surdo e comunidade escolar. Entretanto é dever do intérprete informar à comunidade escolar questões relativas ao surdo: cultura e identidade para uma melhor interação entre professor e aluno e para que o educador faça adaptações curriculares. A comunidade surda e pesquisadores vêm refletindo o papel do intérprete de sala de aula.

TIL3: Não respondeu.

Fonte: Elaborado pelos autores com base nos dados da pesquisa.

A nona questão buscou identificar as concepções dos entrevistados a respeito da formação e da atuação do TIL em sala de aula regular e indicar as melhorias necessárias. De modo geral, os participantes deste estudo afirmaram que sua formação pode ser ampliada. O entrevistado TIL2 afirmou a necessidade de se refletir "sobre o papel do intérprete, entendendo que é um sujeito ativo no processo de ensino aprendizagem do aluno surdo". 
Observa-se que a função do TIL não está clara e, por isso, pesquisas e trabalhos a respeito precisam ser divulgados. No Quadro 9, TIL3 ressalta a importância do contato com a comunidade surda para o aprimoramento da sua atuação profissional. Certamente, estar em contato com essa comunidade fará toda diferençara na vida do TIL, por ampliar seu conhecimento de mundo sobre a cultura surda e as necessidades espaciais da pessoa surda. Por exemplo, em uma festa ou reunião social, deve-se lembrar de reservar um espaço para o descanso de copos e taças, pois os surdos precisam das mãos livres para interagir. Esse conhecimento advém do contato direto com a comunidade surda.

Quadro 9: Formação e atuação do tradutor-intérprete de Libras em sala de aula regular

\section{Que precisa ser melhorado em relação à formação e atuação do tradutor-intérprete de} Libras em sala de aula regular?

TLL1: Os professores precisam se capacitar.

TIL2: Refletir sobre o papel do intérprete entendendo que este é um sujeito ativo no processo de ensino aprendizagem do aluno surdo. Assim alguns educadores vêm refletindo que no processo de inclusão o intérprete atue como professor orientador, ou seja, professor-intérprete.

TIL3: Para ajudar na formação, o profissional precisa de maior contato com a comunidade surda.

Fonte: Elaborado pelos autores com base nos dados da pesquisa.

Por fim, os entrevistados foram questionados sobre o que falta ser ajustado para uma inclusão de qualidade. De modo geral, em suas respostas, expostas no Quadro 10, eles sugeriram que professores e demais profissionais da educação precisam ter conhecimento sobre a cultura da comunidade surda e sobre a Libras. Também abordaram a necessidade de adequar os materiais de ensino para o aluno surdo, especialmente no que se refere aos textos escritos. Isso mostra que a resposta está de acordo com o que dizem os pesquisadores da área (cf. ALMEIDA, 2010; LACERDA, 2010; ROCHA, 2009), concordando também com os documentos que regulamentam a Libras e a atuação do TIL no Brasil. 
Quadro 10: Ajustes necessários à inclusão do aluno surdo em escola regular

\section{O que falta ser ajustado para uma inclusão próspera e de qualidade do aluno surdo em escola regular?}

TIL1: Falta conhecer a cultura e a identidade surda, o conhecimento teórico sobre a Libras e adaptação de materiais.

TIL2: Tudo. Uma inclusão responsável deve repensar toda organização do ensino regular. Não basta garantir o acesso ao intérprete ao estudante surdo, é necessário pensar que este aluno possui um pensamento orientado a partir de uma base visual espacial em função de sua língua materna (Libras). O surdo precisa estar em contato constante com usuários de Libras para que seu aprendizado seja efetivado. No ensino regular o surdo estabelece contato comunicativo somente com o intérprete ficando muitas vezes excluído dentro da própria sala de aula.

TIL3: É preciso que os profissionais da escola e a comunidade também procurem conhecer a comunidade surda, a identidade e cultura.

Fonte: Elaborado pelos autores com base nos dados da pesquisa.

A resposta de TIL2 chama atenção para algo importante: a relação intersubjetiva do surdo com seus pares e com pessoas que conheçam a Libras, a fim de que a pessoa surda seja, de fato, incluída. Sem o conhecimento da Libras a inclusão social e escolar do surdo não ocorrerá de modo eficaz e positivo.

\section{Considerações Finais}

O surdo, muitas vezes, não consegue interagir com outras pessoas, por causa do desconhecimento da língua de sinais pela comunidade ouvinte, tendo a necessidade do auxílio de um tradutor-intérprete de Libras (TIL), como observado nas respostas do questionário apresentado aos TIL que atuam na cidade de Londrina.

Os dados colhidos por meio do questionário mostram que a relação entre ouvintes e surdos, em contexto de ensino, pode variar, mostrando-se positiva ou não, embora, aparentemente, haja interesse de ambas as partes na interlocução. Os entrevistados também ressaltaram a importância do contato com surdos, com sua comunidade e cultura para o bom desempenho do TIL. Apesar de, por meio de um Decreto, se exigir uma formação adequada aos TIL (BRASIL, 2005), as respostas ao questionário mostraram que isso nem sempre 
ocorre. Haja vista questões básicas sobre a Libras, como o fato de ser uma língua, e não uma forma de linguagem, não parecem claras para os entrevistados.

Segundo os participantes da pesquisa, ainda é preciso aprofundar reflexões sobre a função do TIL em sala de aula, deixando claro que o agente formador é o professor, e não o TIL. Compreende-se que esses profissionais devem conhecer não somente a cultura e a identidade surda, mas aproximar-se também dos familiares e amigos do surdo, visando promover sua inclusão, participando assim da divulgação da cultura surda entre os ouvintes.

Ainda há muito para se melhorar no que diz respeito à inserção do indivíduo surdo na sociedade de forma igualitária e produtiva. Pode-se dizer que a escola e os profissionais da educação não estão preparados para receber o surdo de forma inclusiva (não somente integradora), como também a sociedade não está. As mudanças acontecerão quando houver mais espaços para o surdo se desenvolver socialmente, com maior acessibilidade social e cultural, além de maiores oportunidades de crescimento e fortalecimento de sua autonomia (que depende também do ouvinte). Por fim, são esperados maiores incentivos para que, de forma geral, a sociedade possa aprender mais sobre a comunidade surda, sua língua e cultura.

Enfim, para uma educação realmente transformadora e de qualidade, é preciso que haja interação, convívio social, troca de experiências, enfim, inclusão. Para que isso ocorra, as escolas precisam se preparar para receber alunos com especificidades e necessidades diversas, buscando o melhor método de ensino a cada caso e condições estruturais de acessibilidade.

\begin{abstract}
This work's main goal is to research the role of the Brazilian Sign Language (Libras) translator/interpreter in an inclusive classroom. In order to do so, bibliographic and field research was developed, where a questionnaire was used, as an instrument of data collection. The questionnaire was developed to obtain information regarding the education and actuation of these professionals - who are becoming more and important in times of inclusion - in the classroom. The research revealed that, from the point of view of the interviewees, regular study has been beneficial to the deaf, offering them better learning and developing conditions, although some teachers and education agents are not yet prepared to receive these students adequately, in regular classes for basic education.
\end{abstract}

Keywords: Teaching. Inclusion. Brazilian Sign Language. Libras Translator/Interpreter. 


\section{Notas}

\footnotetext{
${ }^{1}$ Observamos que o projeto de Lei $\mathrm{n}^{\circ} 15$, de 2018, elaborado pelo Programa e-Cidadania, foi rejeitado por Comissão em decisão terminativa (art. $91, \S 5^{\circ}$, do RISF) e já se encontra arquivada.

${ }^{2}$ Diferentemente das línguas orais, as de sinais são línguas visuais-espaciais utilizadas pela comunidade surda. Apesar disso, "no que concerne à modalidade de percepção e produção, o uso do termo 'fonologia' tem sido usado para referir-se também ao estudo dos elementos básicos das línguas de sinais" (UNIVERSIDADE DE SANTA CATARINA, 2018, s/p).
}

${ }^{3}$ Por exemplo, tradução da língua portuguesa (língua fonte) para a língua espanhola, língua inglesa ou Libras (línguas alvo).

\footnotetext{
${ }^{4}$ Aqui, o foco está na tradução de/para a Libras: traduz da Libras para a língua de sinais espanhola, ou da Libras para a língua portuguesa, ou o movimento contrário (dessas línguas orais para a Libras).

5 Apesar de ter aumentado muito nos últimos anos, nossa experiência na área mostra que ainda faltam profissionais para atuar como TIL.

${ }^{6}$ Disponível em: <https://feneis.org.br/>. Acesso em: maio 2019.
}

\section{Referências}

ALMEIDA, Elomena Barbosa. O papel de professores surdos e ouvintes na formação do tradutor-intérprete de língua brasileira de sinais. 2010. $111 \mathrm{f}$. Dissertação (Mestrado em Educação) - Universidade Metodista de Piracicaba, Piracicaba, 2010.

BRASIL. LEI No 7.853, DE 24 DE OUTUBRO DE 1989. Dispõe sobre o apoio às pessoas portadoras de deficiência, sua integração social, sobre a Coordenadoria Nacional para Integração da Pessoa Portadora de Deficiência - Corde, institui a tutela jurisdicional de interesses coletivos ou difusos dessas pessoas, disciplina a atuação do Ministério Público, define crimes, e dá outras providências. Disponível em: <http://www.planalto.gov.br/ccivil 03/leis/L7853.htm>. Acesso em: dez. 2018.

BRASIL. LEI N ${ }^{\circ}$ 10.098, DE 19 DE DEZEMBRO DE 2000. Estabelece normas gerais e critérios básicos para a promoção da acessibilidade das pessoas portadoras de deficiência ou com mobilidade reduzida, e dá outras providências. Disponível em: <http://www.planalto.gov.br/ccivil_03/leis/L10098.htm>. Acesso em: dez. 2018.

BRASIL. LEI No 10.436, DE 24 DE ABRIL DE 2002. Dispõe sobre a Língua Brasileira de Sinais - Libras e dá outras providências. Disponível em: <http://www.planalto.gov.br/ccivil_03/leis/2002/110436.htm>. Acesso em: dez. 2018.

BRASIL. DECRETO No 5.626, DE 22 DE DEZEMBRO DE 2005. Regulamenta a Lei $\mathbf{n}^{\mathbf{0}}$ 10.436, de 24 de abril de 2002, que dispõe sobre a Língua Brasileira de Sinais - Libras, e o art. 18 da Lei $\mathbf{n}^{\mathbf{0}} \mathbf{1 0 . 0 9 8}$, de 19 de dezembro de 2000. Disponível em: <http://www.planalto.gov.br/ccivil_03/_ato2004-2006/2005/decreto/d5626.htm>. Acesso em: dez. 2018. 
BRASIL. LEI No 12.319, DE $1^{\circ}$ DE SETEMBRO DE 2010. Regulamenta a profissão de Tradutor e Intérprete da Língua Brasileira de Sinais - LIBRAS. Disponível em: <http://www.planalto.gov.br/ccivil_03/_Ato2007-2010/2010/Lei/L12319.htm>. Acesso em: dez. 2018.

BRASIL. LEI N ${ }^{\circ}$ 12.796, DE 4 DE ABRIL DE 2013. Altera a Lei no 9.394, de 20 de dezembro de 1996, que estabelece as diretrizes e bases da educação nacional, para dispor sobre a formação dos profissionais da educação e dar outras providências. Disponível em: 〈http://www.planalto.gov.br/ccivil_03/_ato2011-2014/2013/lei/112796.htm>. Acesso em: dez. 2018.

BRASIL. Programa e-Cidadania. Libras como disciplina na escola pública. Sugestão n. 15, de 2018. Disponível em: <https://www25.senado.leg.br/web/atividade/materias//materia/133903>. Acesso em: 10 dez. 2018.

FILIETAZ, Marta R. Proença. Atuação do tradutor e intérprete de língua de sinais/ língua portuguesa no IES. 2008. Disponível em: <http://www.uel.br/eventos/seminariosurdez /pages/arquivos/palestra_mesa_03_01.pdf>. Acesso em: dez. 2018.

GIL, Antonio Carlos. Métodos e técnicas de pesquisa social. 6.ed. São Paulo: Atlas, 2008.

LACERDA, Cristina Broglia Feitosa de. Tradutores e intérpretes de Língua Brasileira de Sinais: formação e atuação nos espaços educacionais inclusivos. Cadernos de Educação, FaE/PPGE/UFPel, Pelotas, n.36, p.133-153, maio/agosto 2010.

MARCONI, Marina de Andrade; LAKATOS, Eva Maria. Fundamentos de metodologia científica. 5.ed. São Paulo: Atlas, 2003.

MINISTÉRIO DA EDUCAÇÃO. Direito à educação: subsídios para a gestão dos sistemas educacionais: orientações gerais e marcos legais. 2.ed. Org. de BLATTES, Ricardo Lovatto. Brasília: MEC / SEESP, 2006. Disponível em: <http://portal.mec.gov.br/seesp/arquivos/pdf/direitoaeducacao.pdf $>$. Acesso em: dez. 2018.

PETTER, Margarida. Linguagem, língua, linguística. In: FIORIN, José Luiz (Org.). Introdução à Linguística. 5.ed. São Paulo: Contexto, 2004, p.11-24.

QUADROS, Ronice Muller de. O tradutor e intérprete de língua brasileira de sinais e língua portuguesa: Programa Nacional de Apoio a Educação de Surdos. Brasília: MEC; SEESP, 2004. Disponível em: http://portal.mec.gov.br/seesp/arquivos/pdf/tradutorlibras.pdf Acesso em: dez. 2018.

ROCHA, Solange Maria da. Antíteses, díades, dicotomias no jogo entre memória e apagamento presentes nas narrativas da história da educação de surdos: um olhar para o Instituto Nacional de Educação de Surdos (1856/1961). 2009. 160 f. Tese (Doutorado em Educação) - Pontifícia Universidade Católica do Rio de Janeiro. Rio de Janeiro, 2009. 
ROSA, Andrea da Silva. Entre a visibilidade da tradução da língua de sinais e a invisibilidade da tarefa do intérprete. Campinas, SP: Arara Azul, 2005.

SECRETARIA DE COMUNICAÇÃO SOCIAL DO SENADO FEDERAL. "Libras pode se tornar disciplina obrigatória nas escolas públicas". Senado Notícias. Brasília: DF, 2018. Disponível em: <https://www12.senado.leg.br/noticias/materias/2018/10/05/libras-pode-setornar-disciplina-obrigatoria-nas-escolas-publicas>. Acesso em: dez. 2018.

UNIVERSIDADE DE SANTA CATARINA. Coleção Letras-Libras: eixo formação básica: unidade 4: fonologia da língua de sinais. Disponível em: <http://www.libras.ufsc.br/colecao LetrasLibras/eixoFormacaoBasica/foneticaEFonologia/scos/cap15009/2.html>. Acesso em: dez. 2018. 